\title{
Regioselective Synthesis of Some Thio Analogues of Quinolone Antibacterials via Borate Complex of Quinolone Carboxylic Acid Catalyzed by DABCO under Microwave Irradiation
}

\author{
SHADI H. RAEIAT ${ }^{1}$ and AZAR TAHGHIGHI ${ }^{1,2^{*}}$ \\ ${ }^{1}$ Department of Chemistry, School of Science, Alzahra University, Vanak, Tehran, Iran \\ ${ }^{2}$ Malaria and Vector Research Group (MVRG), Biotechnology Research Center (BRC), \\ Pasteur Institute of Iran, Tehran, Iran \\ atahghighi2009@gmail.com
}

Received 3 March 2014 / Accepted 15 March 2014

\begin{abstract}
Regioselective syntheses of some thio analogues were achieved in this paper. Quinolone carboxylic acid were treated with boric acid in acetic anhydride to produce boron complex, which is then reacted with mercapto compounds to afford quinolone derivatives in high yields.
\end{abstract}

Keywords: Quinolone, Boron complex, DABCO, Regioselective synthesis

\section{Introduction}

Quinolones have become a major class of antibacterial agents, which are under extensive clinical development. They have an attraction because of their extremely potent activity, rapid bacterial effects and low incidence of resistance development ${ }^{1}$. Most of the quinolone antibacterial researches have been focused on the functionality at C-7 position since the introduction of norfloxacine $\mathbf{1}$ and ciprofloxacine $\mathbf{2}$ (Scheme1).

Moreover C-7 substituent is the most adaptable site for chemical change and is an area that determines potency and target preference. A five or six membered ring is the most commonly found substitution at position C-7, for example, ciprofloxcine and norfloxacine that are widely used as antibiotics in wide range, have piperazine substitution at C-7 position (Scheme 1). Fluoro quinolones with 7-piperazinyl moiety have been reported to possess potent antibacterial activity ${ }^{2-9}$.

Enhancement of halogen activity by chelating of $\beta$-keto acid, part of quinolonic acid with boron triacetate, has been patented ${ }^{10-11}$. By structure-activity relationships, it has been shown that sulfur atom makes the activity of quinolones twice ${ }^{12}$. In connection with our earlier work $^{13}$ in this communication we wish to report our result from the reaction of 1substituted 6-fluoro-7-chloro-1,4-dihydro-4-oxoquinoline-3-carboxylic acid (1a-b) with various heterocyclic systems under M.W conditions. 
<smiles>[R]n1cc(C(=O)O)c(=O)c2cc(F)c(N3C=CNCC3)cc21</smiles>

1: Ciprofloxacine R=c-Pr, 2: Norfloxacine $\mathrm{R}=\mathrm{CH}_{2} \mathrm{CH}_{3}$

\section{Scheme 1}

\section{Experimental}

Melting points were measured using an Electrothermal 9100 apparatus and are uncorrected. IR spectra were recorded on a Brucker Tensor 27 FT-IR Instrument. ${ }^{1} \mathrm{H}$ NMR spectra were measured with JEOL EX-90A Spectrometer. Elemental analysis was performed by Heroeus CHN-O-rapid elemental analyzer.

General procedure for the synthesis of borate complexes of 1-substituted 7-chloro6-fluoro-4-oxo-1,2-dihydroquinoline-3-carboxylic acid (2a-b)

Acetic anhydride (27.05 g, $0.265 \mathrm{~mol})$ and boric acid (4.65 g,0.075 mol) was stirred at a temperature range of $80-90^{\circ} \mathrm{C}$ for $1 \mathrm{~h}$, and later cooled to $50^{\circ} \mathrm{C}$. An appropriate quinolonic acid, $\mathbf{1 a}$ or $\mathbf{1 b}(0.05 \mathrm{~mol})$ was added to this solution with constant stirring and the mixture was refluxed for $2 \mathrm{~h}$. After the completion of reaction, the temperature of solution reduced to $10{ }^{\circ} \mathrm{C}$ and $100 \mathrm{~mL}$ of water was added. The precipitate was filtered, washed with water and dried at $45^{\circ} \mathrm{C}$.

General procedure for the synthesis of 1(ethyl / cyclopropyl)-substituted-6-fluoro7- thio substituted-1,4-dihydro-4-oxo quinoline-3-carboxylic acid (4a-d)

The corresponding boron complex (1 mmol) with an appropriate heterocyclic thiol (3a-3d) (1.1 mmol) in the presence of 1,4-diazabycyclo[2.2.2]octane (DABCO, $0.03 \mathrm{~g}, 0.3 \mathrm{mmol}$ ) was exposed under MW Irradiation, in DMSO for 8-10 min. The progress of the reaction was monitored by TLC, using ethyl acetate/n-hexane $3 / 1$ as eluent. Then the mixture was refluxed $(1 \mathrm{~h})$ with $10 \mathrm{~mL}$ sodium hydroxide solution $(2 \mathrm{M})$. After neutralization of the mixture with acetic acid, the precipitate was filtered and washed with methanol-water (1:1) to afford the corresponding derivatives (4a-d).

1-Ethyl-6-fluoro-4-oxo-7-(5-methyl-1H-1,2,4-triazol-3-ylthio)-1,4-dihydroquinoline-3carboxylic acid (4a)

Yield: 91\%, m.p. $270{ }^{\circ} \mathrm{C}$ (decomposed). ${ }^{1} \mathrm{H}$ NMR (90 MHz, DMSO-d 6 ) ( $\delta$ ppm): $1.4(\mathrm{t}, 3 \mathrm{H},-$ $\mathrm{CH}_{3}$ ), 1.9 (s, 3H, - $\mathrm{CH}_{3}$ ), 4.0 (br s, $\left.1 \mathrm{H},-\mathrm{NH}-\right), 4.7$ (q, 2H, $\left.-\mathrm{CH}_{2}-\right), 8.0$ (d, $\left.1 \mathrm{H}, \mathrm{Ph}\right), 8.6(\mathrm{~d}, 1 \mathrm{H}$, $\mathrm{Ph}), 9.4$ (s, $1 \mathrm{H},=\mathrm{CH}-), 11.4(\mathrm{~s}, 1 \mathrm{H},-\mathrm{COOH})$. Anal. Calcd for $\mathrm{C}_{15} \mathrm{H}_{13} \mathrm{FN}_{4} \mathrm{O}_{3} \mathrm{~S}: \mathrm{C}, 51.72 ; \mathrm{H}$, 3.76; N, 16.08. Found: C, 51.39; H, 3.53; N, 16.37\%.

1-Ethyl-6-fluoro-4-oxo-7-(5-phenyl-1H-1,2,4-triazol-3-ylthio)-1,4-dihydroquinoline-3carboxylic acid (4b)

Yield: 90\%, m.p. $275{ }^{\circ} \mathrm{C}$ (decomposed). ${ }^{1} \mathrm{H}$ NMR (90 MHz, DMSO-d 6 ) $(\delta \mathrm{ppm}): 1.2(\mathrm{t}, 3 \mathrm{H}$, $-\mathrm{CH}_{3}$ ), 4.3 (q, 2H, - $\mathrm{CH}_{2}$ ), 5.4 (br s, 1H, -NH-), 7.4 (m, 5H, Ph), 8.1 (dd, 2H, Ph), 8.9 (s, 1H, $=\mathrm{CH}-), 10.8(\mathrm{~s}, 1 \mathrm{H},-\mathrm{COOH})$. Anal.Calcd for $\mathrm{C}_{20} \mathrm{H}_{15} \mathrm{FN}_{4} \mathrm{O}_{3} \mathrm{~S}: \mathrm{C}, 58.53 ; \mathrm{H}, 3.68 ; \mathrm{N}, 13.65$. Found: C, 58.35; H, 3.88; N, 13.76\%. 
1-Cyclopropyl-6-fluoro-4-oxo-7-(1H-1,2,4-triazol-3-ylthio)-1,4-dihydroquinoline-3carboxylic acid (4c)

Yield: 93\% m.p. $265{ }^{\circ} \mathrm{C}$ (decomposed). ${ }^{1} \mathrm{H}$ NMR (90 MHz, DMSO-d 6 ) $(\delta \mathrm{ppm}): 0.3$ (m, 2H, $-\mathrm{CH}_{2}-$ ), 0.7 (m, 2H, - $\mathrm{CH}_{2}-$ ), 2.1 (m, 1H, -CH.), 4.7 (br s, 1H, -NH-), 8.1 (d, 1H, Ph), 8.6 (d, $1 \mathrm{H}, \mathrm{Ph}), 9.1(\mathrm{~s}, 1 \mathrm{H},=\mathrm{CH}-), 11.8(\mathrm{~s}, 1 \mathrm{H},-\mathrm{COOH})$. Anal.Calcd for $\mathrm{C}_{15} \mathrm{H}_{11} \mathrm{FN}_{4} \mathrm{O}_{3} \mathrm{~S}$ : C, 52.02; H, 3.20; N, 16.18. Found: C, 52.25; H, 3.22; N, 15.93\%.

3-Methyl-7-oxo-10-ethyl-7,10-dihydro-1,2,4-triazolo[3',4':2,3]-1,3,4-thiadiazino[5,6g]quinoline-8-carboxylic acid (4d)

Yield: $80 \%$ m.p. $278^{\circ} \mathrm{C}$ (decomposed). ${ }^{1} \mathrm{H}$ NMR (90 MHz, DMSO-d 6 ) $(\delta \mathrm{ppm}): 1.3(\mathrm{t}, 3 \mathrm{H},-$ $\mathrm{CH}_{3}$ ), 2.1 (s, 3H, $-\mathrm{CH}_{3}$ ), 4.4 (q, 2H, $-\mathrm{CH}_{2}$ ), 7.2 (br s, $\left.1 \mathrm{H}, \mathrm{Ph}\right), 7.8$ (br s, $\left.1 \mathrm{H}, \mathrm{Ph}\right), 8.1(\mathrm{~s}, 1 \mathrm{H}$, $=\mathrm{CH}-$ ), 10-11 (br s, 2H, -NH- and -COOH). FT-IR $\left(\mathrm{KBr}, \mathrm{cm}^{-1}\right)$ : 3426 (acidic OH), 3180, ($\mathrm{NH}$ Secondary amine) 3060, 2934, 1610, 1578, 1721, 1450, 1370. Anal. Calcd for $\mathrm{C}_{15} \mathrm{H}_{13} \mathrm{~N}_{5} \mathrm{O}_{3} \mathrm{~S}$ : C, 52.47; H, 3.82; N, 20.40. Found: C, 52.28; H, 4.01; N, 20.66\%.

\section{Results and Discussion}

The use of boron complex as fluoroborate complex of quinolone carboxylic acid, in order to achieve a pure thio derivative from the reaction of the obtained complexes $\mathbf{2 a - b}$ with various nucleophiles 3a-d has been reported. By synthesis of the intermediates $\mathbf{2 a - b}$, a more positive charge at C-7 position of fluoroquinolone ring is generated. On the other hand by applying DABCO as an efficient catalyst and MW irradiation, the introduction of heterocyclic thiols, classified as poor nucleophiles, became possible.

Compounds 1a-b reacted with boric acid triacetate in acetic anhydride media to obtain complexes of the formula $\mathbf{2 a}$ and $\mathbf{2} \mathbf{b}$ in almost quantitative yields. The $\mathbf{2} \mathbf{a}-\mathbf{b}$ complexes reacted with thiols 3a-c in the presence of DABCO as catalyst and in DMSO as solvent under MW irradiation, to obtain the related 7- thio substituted complexes. A further treatment with $\mathrm{NaOH}$ solution was performed to generate the corresponding fluoroquinolone-3-carboxylic acid sodium salt. Neutralization of the aforesaid salt with acetic acid led to the formation of the final products (Scheme 2). These products were identified by spectroscopic data to be the result of a substitution of thiolat in a heterocyclic system with chlorine in complexes $\mathbf{2 a - b}$ to afford compounds $\mathbf{4 a - c}$.

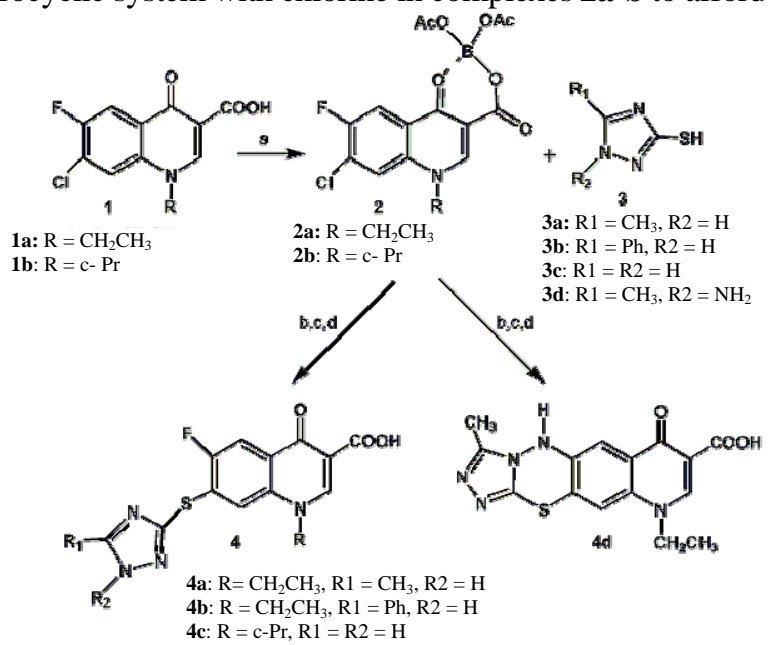

Scheme 2. Synthetic route to compounds 4a-d. Reagents and conditions: a) $\mathrm{H}_{3} \mathrm{BO}_{3}$, $\left(\mathrm{CH}_{3} \mathrm{CO}\right)_{2} \mathrm{O}$; b) DABCO, M.W; c) $\mathrm{NaOH}$, reflux; d) $\mathrm{CH}_{3} \mathrm{COOH}$ 
When 4-amino-5-methyl-1,2,4-triazol-3-thiol 3d reacted with 2a under the mentioned conditions, a single compound was obtained 4d. The spectroscopic and analytical data proved that in this reaction, the bidentate nucleophile has substituted both fluorine and chlorine of 2a to afford a novel heterocyclic system: 3-Methyl-7-oxo-10-ethyl-7,10-dihydro1,2,4-triazolo[3',4':2,3]-1,3,4-thiadiazino[5,6-g]quinoline-8-carboxylic acid (4d).

\section{Conclusion}

A high efficient methodology for the synthesis of 7-thio substituted quinolone carboxylic acid was demonstrated. Various heterocyclic thiols were applied to evaluate the method and considerable substitution yields on C-7 were achieved in relatively low reaction times.

\section{Acknowledgment}

The authors are thankful to Azzahra University Research Council for the partial financial support.

\section{References}

1 Hooper D C and Wolfson J S, Antimicrob Agents Chemother., 1985, 28(5), 716-721.

$2 \quad$ Ball P, Infection, 1994, 22(Suppl 2), 140-147.

3 Ball P, Mandell L, Niki Y and Tillotson G, Drug Saf, 1999, 21(5), 407-421.

4 Ball P, J Antimicrob. Chemother, 2000, 45(5), 557-559.

5 Domagala J M, Heifetz C L, Hutt M P, Mich T F, Nichols J B, Solomon M and Worth D F, J Med Chem., 1988, 31(5), 991-1001.

6 Chu D T, Fernandes P B, Claiborne A K, Pihuleac E, Nordean C W, Maleczka R E and Pernet A G, J Med Chem., 1985, 28(11), 1558-1564.

7 Shen L L, Mitscher L A, Sharma P N, O'Donnell T J, Chu D W, Cooper C S, Rosen T and Pernet A G, Biochem., 1989, 28(9), 3886-3894.

8 De Sarro A and De Sarro G, Curr Med Chem., 2001, 8(4), 371-384.

9 Guo Q, Feng L S, Liu M L, Zhang Y B, Chai Y, Lv K, Guo H Y and Han L Y, Eur J Med Chem., 2010, 45(11), 5498-506.

10 Pulla R M and Venkaiah C N, US Patent 0073030, 2004.

11 Reilly M, US Patent 7456279, 2008.

12 Gallo S, Chevalier J, Mahamoud A, Eyraud A, Pages J M and Barbe J, Int J Antimicrob Agents, 2003, 22(3), 270-273.

13 Hekmat Shoar R, Heravi M M, Pedram L, Raeiat S H and Jaddi Z, Phosphorus Sulfur and Slicon and related Elements., 2005, 180, 2563-2567; DOI: 10.1080/104265090930263 